\title{
Novel ecosystems in ecological restoration and rehabilitation: Innovative planning or lowering the bar?
}

\author{
Michael P Perring ${ }^{1 *}$, Patrick Audet ${ }^{2,3^{*}}$ and David Lamb ${ }^{3}$
}

\begin{abstract}
Stemming from a special symposium at the 2012 inaugural meeting of the Society for Ecological Restoration Australasia in Perth, Western Australia, this special issue editorial addresses novel ecosystems in ecological restoration and the inherent challenges of maintaining the highest standards of environmental stewardship and biological conservation in the face of increasing urbanization, agricultural expansion, and industrialization. Echoing others, we (the Guest Editors) view novel ecosystems as offering opportunities for conservation and restoration in the coming years and a pragmatic recognition that it may not always be possible, or desirable, to overcome adverse consequences of environmental degradation to reinstate historical systems. Being mindful of hubris and taking into account difficulties with identification, novel ecosystems may be viewed as a temporary or interim stage on the way towards the evolution of other future ecosystems able to supply a variety of ecosystem services, while attempting to maintain and enhance biodiversity, function and resilience. Here, a concise summary of contributions to the special issue and their significance to the field of restoration ecology is provided noting that authors were tasked to answer whether novel ecosystems are innovative planning or lowering the bar in ecological restoration. Core themes shared by the manuscripts are elucidated leading to guiding principles and, more importantly, an assessment of how and why restoration priorities are changing in the $21^{\text {st }}$ century.
\end{abstract}

\section{Introduction}

The global environment is changing at an increasingly rapid pace and human activity is influencing many (if not all) of Earth's systems leading some to argue that we have entered a new geological epoch: the Anthropocene (Crutzen 2002). Although most would consider that human well-being has benefited from this socio-economic growth, one pervasive change is the widespread loss of unique biodiversity through increasing urbanisation, agricultural expansion, material resource extraction, and industrialisation; drivers which rank among the greatest threats to conservation and the subsequent delivery of some ecosystem services (Myers et al. 2000; Lenzen et al. 2012). It is within this context that scientists have heeded the need to bridge latest

\footnotetext{
*Correspondence: michael.perring@uwa.edu.au; audet.p@gmail.com 'Ecosystem Restoration and Intervention Ecology Research Group, School of Plant Biology, The University of Western Australia, 35 Stirling Highway, Perth (Crawley), WA 6009, Australia

${ }^{2}$ Northern Forestry Centre, Canadian Forestry Service, Natural Resources Canada, 5320-122nd Street, Edmonton, AB, T6H 3S5, Canada Full list of author information is available at the end of the article
}

ecological theories with contemporary environmental management practices towards an era of restoration in ecology (Suding 2011) and ultimately try to sustain both biodiversity and human well-being (Ellis 2013).

Traditionally, restoration practitioners have targeted the reinstatement of pre-existing (or historical) ecosystems (Hobbs and Cramer 2008). However, given the rise of no-analogue environments and continued environmental change, there is increasing evidence that landscapes now contain new assemblies of abiotic and (or) biotic system components. In some cases, environmental changes (both natural and non-natural) have apparently resulted in the formation of stable alternative ecological states (that is, given the short timescale of human appreciation) that are potentially irreversibly different than pre-existing ones, so-called novel ecosystems (Hobbs et al. 2006, 2009). Evidently, the recognition of novel ecosystems fundamentally challenges whether 'going back to the past' is necessarily the most appropriate restoration outcome for all disturbed landscapes (Jackson and Hobbs 2009;

\section{穴}

(c) 2014 Perring et al.; licensee Springer. This is an Open Access article distributed under the terms of the Creative Commons Attribution License (http://creativecommons.org/licenses/by/2.0), which permits unrestricted use, distribution, and reproduction in any medium, provided the original work is properly credited. 
Hobbs et al. 2011). We are thus challenged to investigate whether we should move away from traditional notions of restoration and revise the manner in which rehabilitation goals are addressed (Seastedt et al. 2008). For example, to what extent are contemporary landscapes natural or novel following disturbances? Should ecological restoration efforts always target historic or pre-disturbance conditions? Should notions of appropriate biological conservation, ecosystem restoration and environmental stewardship depend on whether disturbance factors stem from apparently localised, highly lucrative activities such as mining, or more diffuse changes with no clear 'owner' such as urban expansion or atmospheric pollution?

These widely applicable issues formed the basis of a special symposium at the 2012 inaugural meeting of the Society for Ecological Restoration Australasia in Perth, Western Australia. Culminating from this dialogue, presenters and interested parties were invited to prepare contributions for Ecological Processes addressing the challenges and consequences of novel ecosystems, and this special issue presents a number of perspectives across a wide range of ecological contexts, disturbance regimes and investigative perspectives. Although manuscripts submitted to this project share an Australian investigative outlook, all contributors were asked to refine the outcomes of their research in relation to the following question: Are novel ecosystems innovative planning or, rather, a lowering of the bar for rehabilitation and restoration?

\section{Special issue content}

Contributions to this special issue range from the conceptual underpinnings of novel ecosystems and how ecological theory can be used to inform management, to studies outlining where novel ecosystems may be an appropriate goal for restoration. Other works address issues surrounding ecological monitoring, the identification of novel ecosystems and how uncovering divergent restoration outcomes potentially leads to mechanistic understanding. In all cases, contributors were required to define novelty within their respective investigative contexts.

Perring et al. (2013) have confronted novel ecosystems and their role in rehabilitation and restoration head-on. They detail how novel ecosystems (as originally conceived) arose inadvertently and, therefore, 'simply are'. As such, novel ecosystems should represent neither innovative planning nor lowering the bar, but working out how to manage these systems is necessary both now and into the future. Here, they detail generic options for intervening in novel ecosystems focusing on the potential for these systems to provide valued ecosystem functions and services, as supported by an ongoing long-term experiment in former agricultural land (Perring et al. 2012). Consequently, there may be opportunities in broadening the restoration framework to incorporate novelty, although they caution against hubris and explore concerns raised by the concept.

The opportunities provided by novel ecosystems are then further explored by Sack (2013), particularly the ability to reconnect urban landscapes with nature through planning and design. Building on discussions surrounding 'wild' design and concepts of nature as well as an extensive literature on landscape planning, she contrasts classic restoration goals with those of landscape architecture as an allied discipline. In so doing, it is suggested that urban areas (being both cultural and ecological landscapes) should be ready canvases for designed novel ecosystems which can have ecological function, but at the same time have profound aesthetic manipulation.

Firn et al. (2013) revisit data from a number of experiments to derive a testable framework regarding how to intervene in novel ecosystems characterised by nonnative species, again to promote valued ecosystem functioning. Against a backdrop of alternative stable states theory and state-and-transition models, they suggest that invasive alien plants can be managed by strategic grazing that considers both the current state of a plant community and its desired future state. They prefer a 'whole-ofecosystem' approach for making management decisions, contrasting such an approach to previous strategies that only considered the mitigation of individual species.

The conscious adoption of novel ecosystems as a goal in the rehabilitation of highly disturbed landscapes is suggested by Doley and Audet (2013) through their framework that enables ecologically informed decision making in a mining context. They highlight the incongruity of policy perspectives that require restoration to achieve rapid results against the biological reality that re-establishment of a functioning ecosystem takes time. Similar arguments are advanced by Erskine and Fletcher (2013) who provide evidence that the rehabilitated areas they examined in the Bowen Basin of Queensland, Australia, one of the world's richest coal deposits, have fundamentally different abiotic properties than pre-disturbance conditions. Thus, they question the compliance-driven goal of reinstating highly disturbed landscapes to historical references.

These conceptual viewpoints are complemented by multiple field studies that attempt to quantify whether extant restored systems are novel or not. Reiterating that ecosystem recovery takes time, Majer et al. (2013) argue that determining whether a system is novel or not should also take time. Using ant biodiversity as indicators of suitable habitat, these perspectives are derived following the comparison of two long-term data sets spanning nearly 40 years of monitoring rehabilitated jarrah forest after bauxite mining in Western Australia. Monie et al. (2013) and Florentine et al. (2013) then examine recruitment of plant species and reproductive potential among rehabilitated woodlands both in the Lurg Hills 
and Nurong regions of Victoria, Australia. They infer that, if the composition of actively recruiting vegetation assembly differs to that which is present among reference sites, then ecological barriers may prohibit traditional notions of ecosystem recovery. As such, novel ecosystems may be present.

Finally, the presence of novelty is inferred even more strongly by Audet et al. (2013) in their investigation of forest revegetation following sand mining on North Stradbroke Island, South East Queensland. In cases where sites express divergent developmental trajectories, they discuss how subtle and even seemingly benign differences between the pre-disturbance and post-disturbance environments can lead to starkly different ecological outcomes, with emphasis on potential mechanisms of ecological divergence.

\section{Conclusions}

\section{Changing restoration priorities in the 21 st century}

When taken together, this special issue suggests that it is difficult to determine whether attempts to restore degraded sites will lead to the development of novel instead of natural ecosystems. It may take time to clarify this, one way or the other, and time is a luxury that compliancedriven restoration rarely possesses. The conceptual underpinnings show how novel ecosystems arise out of fundamental ecological processes; for example, the individualistic movement of populations and species as environmental conditions change threshold dynamics and alternative stable states. This suggests that we can use our traditional and growing ecological understanding to improve conservation outcomes for these systems through processes like adaptive management, and that new ecological theory to underpin novel ecosystems is not required. However, the existence of novel ecosystems must be recognized. This existence provides opportunities for conservation and restoration, but demands the development of appropriate interventions as we move towards an era of restoration.

The debate surrounding novel ecosystems (whether regarding its theoretical underpinnings or pragmatic consequences) is taking place at a time when significant changes are underway in international policy circles concerning rehabilitation of degraded lands. Until recently, national and international bodies as well as most funding agencies saw reforestation as the main form of managed terrestrial revegetation with most reforestation being done to increase the supply of timber (Evans 2009). As shown in many of the contributions to this special issue, an increasing emphasis is now being placed on improving the supply of ecosystem services in both terrestrial and aquatic environments ${ }^{\mathrm{a}}$. Of course, ecological restoration which aims to restore a historical trajectory will continue to be relevant in many situations where sites have not been too degraded and where the surrounding landscape remains undamaged. But, the need to deal with severely degraded sites and tailor restoration schemes to also improve human livelihoods means that compromises will have to be made at all stages of environmental planning and management, particularly in an era of climate change (Harris et al. 2006). The type of restoration undertaken will depend on circumstances and local priorities, yet it should be recognized that the types of systems that emerge may differ from the historical antecedent. Some forms of restoration may still encompass many traditionally held restoration goals, but the diversity of possible outcomes (that is, accommodating varying degrees of novelty) means that there could be differences in the numbers of species used, the relative proportion of these and, possibly, the extent to which new ecosystems are managed (for example, imposed grazing or harvesting regimes, fire, and so on $)^{\mathrm{b}}$. At its core, acknowledgment of and then accounting for novel ecosystems in ecological restoration should require a fundamental change in perceptions as to what can be achieved on any given disturbed or degraded landscape based on actual or potential site conditions as opposed to targeting idealised landscapes. Echoing others (Shackelford et al. 2013; Bridgewater et al. 2011), policy and legal frameworks also need to urgently take into account how to deal with the timescales of ecological dynamics versus economic imperatives, especially in the case of the fossil fuel industries (Butt et al. 2013).

Biodiversity conservation is a priority in the 21 st century. However, restoring biodiversity in degraded landscapes on a large scale is technically demanding and usually financially difficult (Menz et al. 2013). In practice, the best approach may be to do so incrementally and in stages, being mindful that current and future approaches will likely always be replaced with something better. Novel ecosystems may represent the best that can now be achieved in some circumstances given environmental and socio-economic changes and the scale of degradation that has occurred. To some, this would be viewed in a negative light, as if restoration ecologists have somehow failed to deliver and thereby lowered the bar since it implies a permanent loss of historical fidelity or integrity. On the other hand, there is growing empirical evidence suggesting that novel ecosystems could be a sound complement to traditional restoration approaches and thereby could be viewed as innovative planning, so long as the highest conditions and requirements of ecological stewardship and biological conservation can be met and upheld; that is, they should not be used as an excuse by developers, regulators or policy makers to allow compromised standards of ecological integrity or conservation. Drawing perspectives from both sides of this debate, we (the Guest Editors) see this as a pragmatic recognition that it may not always be possible to overcome many adverse consequences of environmental degradation. 
More specifically, novel ecosystems may be viewed as a temporary or interim stage on the way towards the evolution of other future ecosystems able to supply a variety of ecosystem services, while attempting to maintain and enhance biodiversity, function and resilience.

\section{Endnotes}

${ }^{a}$ The 2010 Convention on Biological Diversity (CBD) in Nagoya, Japan, explicitly called for restoration to supply ecosystem services (CBD Convention of the Parties 10: Decision X/2; reaffirmed at the subsequent Convention of the Parties 11 at Hyderabad, India, 2012: Decision XI/16). The United Nations Environmental Programme (UNEP) is now also recommending the restoration of degraded ecosystems to secure ecosystem services, address challenges in disaster prevention, secure water supplies, improve carbon sequestration and enhance food security (Nellemann and Corcoran 2010).

${ }^{\mathrm{b}}$ In some situations, managers might seek to restore all ecosystem services, whereas elsewhere they may consider particular attributes (for example, watershed protection) to be of greater importance than biodiversity conservation. Likewise, managers concerned with biodiversity conservation may have to choose between restoring the habitats of an endangered and/or iconic species not previously found in an area versus trying to restore the habitats of all species previously found at a site. Similar choices might need to be made when managers are seeking simultaneously to overcome degradation and improve resilience or functional outcomes.

\section{Competing interests}

The authors declare that they have no competing interests.

\section{Authors' contributions}

MPP drafted the first version of this manuscript and PA and DL subsequently contributed ideas to and edited all sections. All authors read and approved the final manuscript.

\section{Acknowledgements \\ The Guest Editors wish to thank the management and editorial staff of Ecological Processes (particularly Dr Yegang Wu and Jo-an Soquias) for their support of this special issue project, and comments from two anonymous reviewers that improved this editorial.}

\section{Author details \\ ${ }^{1}$ Ecosystem Restoration and Intervention Ecology Research Group, School of Plant Biology, The University of Western Australia, 35 Stirling Highway, Perth (Crawley), WA 6009, Australia. ${ }^{2}$ Northern Forestry Centre, Canadian Forestry Service, Natural Resources Canada, 5320-122nd Street, Edmonton, AB, T6H 3S5, Canada. ${ }^{3}$ Centre for Mined Land Rehabilitation, Sustainable Minerals Institute, The University of Queensland, Sir James Foots Building, Brisbane (St Lucia), QLD 4072, Australia.}

Received: 16 December 2013 Accepted: 18 February 2014 Published: 12 March 2014

\section{References}

Audet P, Gravina A, Glenn V, McKenna P, Vickers H, Gillespie M, Mulligan D (2013) Structure of vegetation development on rehabilitated North Stradbroke Island: above/ belowground feedback may facilitate alternative ecological outcomes. Ecol Process 2:20
Bridgewater P, Higgs ES, Hobbs RJ, Jackson ST (2011) Engaging with novel ecosystems. Front Ecol Environ 9:423

Butt N, Beyer HL, Biggs D, Maggini R, Mills M, Renwick AR, Seabrook LM, Possingham HP (2013) Biodiversity risks from fossil fuel extraction. Science 342:425-426

Crutzen PJ (2002) Geology of mankind. Nature 415:23

Doley D, Audet P (2013) Adopting novel ecosystems as suitable rehabilitation alternatives for former mine sites. Ecol Process 2:21

Ellis EC (2013) Sustaining biodiversity and people in the world's anthropogenic biomes. Curr Opin Environ Sustain 5:368-372

Erskine P, Fletcher A (2013) Are novel open woodland ecosystems created by coal mines? Rehabilitation outcomes in central Queensland. Ecol Process 2:33

Evans J (ed) (2009) Planted Forests: Uses, Impacts and Sustainability. Food and Agriculture Organisation of the United Nations, Rome, and CAB International, Wallingford

Firn J, Price JN, Whalley RDB (2013) Using strategically applied grazing to manage invasive alien plants in 'novel grasslands'. Ecol Process 2:26

Florentine SK, Gardner J, Graz P, Moloney S (2013) Plant recruitment and survival as indicators of ecological restoration in abandoned pasture land in Nurcoung, Victoria, Australia. Ecol Process 2:34

Harris JA, Hobbs RJ, Higgs E, Aronson J (2006) Ecological restoration and global climate change. Restor Ecol 14:170-176

Hobbs RJ, Cramer VA (2008) Restoration ecology: Interventionist approaches for restoring and maintaining ecosystem function in the face of rapid environmental change. Ann Rev Environ Res 33:39-61

Hobbs RJ, Arico S, Aronson J, Baron JS, Bridgewater P, Cramer VA, Epstein PR, Ewel JJ, Klink CA, Lugo AE, Norton D, Ojima D, Richardson DM, Sanderson EW, Valladares F, Vila M, Zamora R, Zobel M (2006) Novel ecosystems: Theoretical and management aspects of the new ecological world order. Global Ecol Biogeogr 15:1-7

Hobbs RJ, Higgs E, Harris JA (2009) Novel ecosystems: implications for conservation and restoration. Trends Ecol Evol 24:599-605

Hobbs RJ, Hallett LM, Ehrlich PR, Mooney HA (2011) Intervention ecology: applying ecological science in the twenty-first century. Bioscience 61:442-450

Jackson ST, Hobbs RJ (2009) Ecological restoration in the light of ecological history. Science 325:567-569

Lenzen M, Moran D, Kanemoto K, Foran B, Lobefaro L, Geschke A (2012) International trade drives biodiversity threats in developing nations. Nature 486:109-112

Majer JD, Heterick B, Gohr T, Hughes E, Mounsher L, Grigg A (2013) Is thirty-seven years sufficient for full return of the ant biota following restoration? Ecol Process 2:19

Menz MHM, Dixon KW, Hobbs RJ (2013) Hurdles and opportunities for landscape-scale restoration. Science 339:526-527

Monie K, Florentine SK, Palmer G (2013) Plant recruitment and functionality traits as bioindicators of ecological restoration success in the Lurg Hills district, Victoria, Australia. Ecol Process 2:27

Myers N, Mittermeier RA, Mittermeier CG, da Fonseca GAB, Kent J (2000) Biodiversity hot spots for conservation priorities. Nature 403:803-808

Nellemann C, Corcoran E (2010) Dead Planet. Biodiversity and Ecosystem Restoration for Sustainable Development. A Rapid Response Assessment. United Nations Environmental Program, Nairobi, Living Planet

Perring MP, Standish RJ, Hulvey KB, Lach L, Morald TK, Parsons R, Didham RK, Hobbs RJ (2012) The Ridgefield multiple ecosystem services experiment: Can restoration of former agricultural land achieve multiple outcomes? Agric Ecosys Environ 163:14-27

Perring MP, Standish RL, Hobbs RJ (2013) Incorporating novelty and novel ecosystems into restoration planning and practice in the 21st century. Ecol Process 2:18

Sack C (2013) Landscape architecture and novel ecosystems: ecological restoration in an expanded field. Ecol Process 2:35

Seastedt TR, Hobbs RJ, Suding KN (2008) Management of novel ecosystems: Are novel approaches required. Front Ecol Environ 6:547-553

Shackelford N, Hobbs RJ, Burgar JM, Erickson TE, Fontaine JB, Laliberté EL, Ramalho CE, Perring MP, Standish RJ (2013) Primed for change: developing ecological restoration for the 21st century. Restor Ecol 21:297-304

Suding KN (2011) Toward an era of restoration in ecology: successes, failures, and opportunities ahead. Ann Rev Ecol Evol S 42:465-487

doi:10.1186/2192-1709-3-8

Cite this article as: Perring et al:: Novel ecosystems in ecological restoration and rehabilitation: Innovative planning or lowering the bar? Ecological Processes 2014 3:8. 